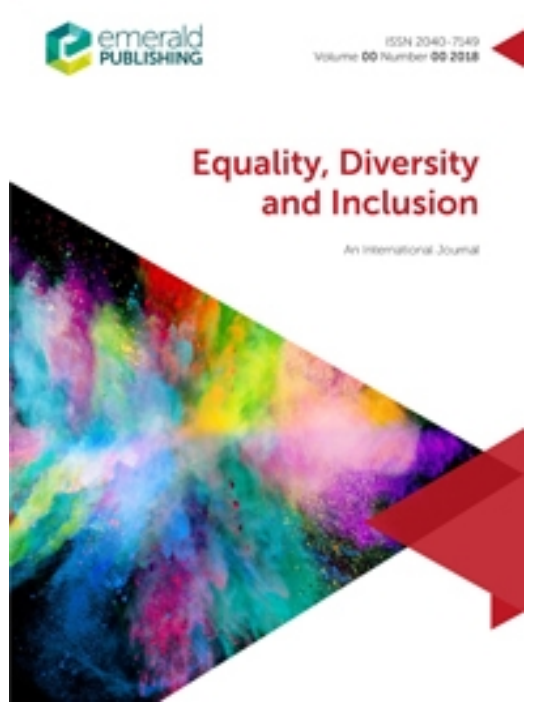

\title{
Diversity in the work-life interface: Introduction to the Special Issue
}

\begin{tabular}{|r|l|}
\hline Journal: & Equality, diversity and inclusion: An international journal \\
\hline Manuscript ID & EDI-04-2020-0097 \\
\hline Manuscript Type: & Original Article \\
\hline Keywords: & $\begin{array}{l}\text { Intersectionality, Work-life, Work-family, Role conflict, Immigrants, } \\
\text { Gender }\end{array}$ \\
\hline
\end{tabular}

\section{SCHOLARONE \\ Manuscripts}




\title{
DIVERSITY IN THE WORK-LIFE INTERFACE
}

\begin{abstract}
Purpose: This article serves as an introduction to six articles featured in a special issue on diversity in the work-life interface. This collection of papers contains research that contemplates the work-life interface in different geographical and cultural contexts, that explores the work-life experiences of minority, marginalized, and/or under-researched groups of workers, and that takes into account diverse arrangements made to fulfil both work and nonwork responsibilities.
\end{abstract}

Design/Methodology/Approach: This introductory article first summarizes some of the emerging research in this area, introduces the papers in this Special Issue and links them to these themes, and ends with highlighting the importance of using an intersectional lens in future investigations of the work-life interface.

Findings: These six articles provide empirically based insights as well as new theoretical considerations for studying the interface between paid work and personal life roles. Compelling new research directions are identified.

Originality: Introducing the new articles in this Special Issue and reviewing recent research in this area brings together work-life interface scholarship and diversity management studies, and points to the necessity for future investigations to take an intersectional and contextualized approach to their subject matter.

\section{Introduction}

Research that explores the interface between paid work and personal life has been hugely prolific over the last two decades. Scholars have explored aspects such as the conceptualisation of relationships between work and family domains, such as conflict, enrichment, balance, and segmentation/integration (Carlson et al., 2009; Gatrell et al., 2013); antecedents and outcomes of these constructs (Derks et al., 2016; French et al., 2018); lived 
experiences of these phenomena in different occupations (Beigi et al., 2017; Ford and Collinson, 2011; Guillaume and Pochic, 2009); differences in work-family conflict and its impact according to geographical region (Drummond et al., 2017; Masuda et al., 2019); tactics for establishing and maintaining boundaries between work and family domains (Cruz and Meisenbach, 2018); decision making about work-family issues (Lupu et al., 2018); and organizational and legislative policy and practices designed to help workers fulfil dual roles (Cannizzo et al., 2019; Kossek et al., 2010). This body of research has generated important empirical and theoretical insights suggesting that work-life negotiations largely remain a struggle for individual workers, and also produced valuable and much-needed recommendations for organisations and policy makers.

There have been criticisms of the current body of literature, however, and chief among these is its restricted sample base. In other words, much of the literature looking at the worklife interface typically focuses on the experiences of white, heterosexual mothers of young children, who are engaged in white collar work and living in nuclear family households in Western societies (Özbilgin et al., 2011). This 'ideal work-life balancer' that emerges from the extant research informs the way in which work-life issues continue to be framed and studied. This is not surprising because historically 'the relationship between work and life first became a focus of interest as growing numbers of women sought paid employment outside the home, following the Second World War' (Kelliher et al., 2019, p. 99). As many women still had to fulfil their role as mothers, wives and homemakers, the issue of balancing these responsibilities with paid employment created the need to understand and interpret these experiences (Gatrell et al., 2013). We are not discounting the difficulties that mothers experience in balancing paid and non-paid work and would argue that it is paramount to continue research in this area. However, the sole focus on white heterosexual Western mothers of young children is problematic in a number of ways. 
Firstly, this persistent focus on a specific group means that empirically, we still have very little understanding of work-life issues among diverse employee groups, including immigrant populations, ethnic and religious minorities, workers with disabilities, and individuals with non-traditional family structures, such as members of the LGBT community. In Voydanoff's (2002) conceptual model of the work-life interface, adaptive strategies predict work and personal life characteristics, which in turn predict work, personal life, and individual outcomes. These outcomes are moderated by social categories and coping resources. Members of diverse employee groups can thus be expected to have a diverse range of adaptive strategies and resources that impact their experiences of the work-life interface. Understanding these differences is crucial in order to move research and theorising around work-life interface forward both empirically and theoretically. Moreover, recent research suggests that in order to understand the complex and at times contradictory experiences of people in relation to their ability to manage work and life demands, it is important to consider individuals' identities (Hamidullah and Riccucci, 2017; Ray and Jackson, 2013).

Secondly, and related to the above, work and family issues are also closely linked to different cultural norms and values which are different from those of dominant groups in the West (Mortazavi et al., 2009). For example, cultural settings may determine household arrangements that may be very different from nuclear households common in the West, for instance multigenerational households and/or those containing extended family members (Khokher and Beauregard, 2014; Knodel and Chayovan, 2012). Cultural contexts also impact on the construction and meanings of gender roles and gender ideologies - an issue that is crucial in understanding work-life balance issues such as the domestic division of labour (Kurowska, 2018). Finally, different cultural contexts have varying economic and social policies that impact organizational interpretations and individual experiences of the work-life interface (Klarsfeld et al., 2014; Lewis and Beauregard, 2018). Minimal exploration of different cultural 
contexts means that many of the concepts and theories that draw on the ideal work-life balancer' in the Western context as outlined above may not be (as) relevant or applicable to different cultural contexts. It also means that exploring these links between diversity and employees' work-life strategies and resources represent a fruitful avenue of research for a field that is only beginning to expand beyond its white, middle-class, Western origins.

Finally, the literature's focus on a particular group of people may limit the extent to which this research can inform organisational and broader state policy. For instance, Kelliher et al.'s (2019) review suggests that blind spots remain in understanding the work-life balance of those without children, of those with other care responsibilities (such as eldercare), or of those with non-standard schedules of work or in non-traditional employment, for example those who are self-employed or on zero-hours or part-time contracts. Self-employment is particularly interesting as we have witnessed an exponential growth in the gig economy and the growing precarity of employment arrangements in the last decade (Abraham et al., 2018; Healy et al., 2017). The non-standard employment context warrants greater exploration by work-life researchers as typical organisational and state-wide policies that address some work-life issues may not exist or be applicable in these kinds of settings.

As is clear, despite prolific research on the work-life interface there still remain gaps and blind spots, particularly in regard to the inclusion of more diverse population samples. This Special Issue seeks to fill some of these gaps. In our call for papers, we were particularly interested in research that contemplates the work-life interface in different geographical and cultural contexts, that explores the work-life experiences of minority, marginalized, and/or under-researched groups of workers, and that takes into account diverse arrangements made to fulfil both work and non-work responsibilities. In the sections below we first summarize some of the emerging research on these themes before introducing the papers in this Special Issue and linking them to these themes. Finally, we highlight the importance of using an 
intersectional lens in future investigations of the work-life interface.

\section{Research on the work-life interface in diverse geographical and cultural contexts}

Moving away from the individual-level conceptualization of the work-life interface that characterized early work in this area, a number of scholars over the past decade have contributed to theorizing the work-life interface as culturally bound. Cultural context is important in relation to the work-life interface for two main reasons. First, understandings of the concepts of 'work' and 'personal life', and of how they intersect, vary considerably across the globe. Secondly, policies addressing the issues inherent in balancing paid work and personal life (such as support for personal or family commitments) differ significantly from country to country.

With regard to differences in conceptualizing the work-life interface, Powell et al. (2009) focused on national culture and argued for the inclusion of cultural dimensions from Hampden-Turner and Trompenaars' (2000) framework of cultural variation and House et al.'s (2004) Project GLOBE, such as collectivism, human orientation, gender egalitarianism and specificity/diffusion, in theories of how activities and resources from either work or personal life may conflict with or enhance activities and resources from the other domain. Chandra (2012) also highlighted that gendered ideologies are crucial to understanding the work-life interface in different countries. In nations where the majority of workplaces are maledominated and there are strongly prevailing patriarchal ideologies, the issues and discussions around the work-life interface may be very different to those in Western contexts as socialization plays a key role in determining how work-life issues are understood and experienced. For instance, organizational work-life policies in many Asian countries tend to focus on the issue of long working hours, while traditional gender norms go unquestioned and the gendered division of labour thus prevails both in the workplace and the household (Chandra, 2012). The work-life interface is therefore perceived as a matter to be handled by 
individuals and not an issue with which employers should be concerned. Building on these ideas, Lewis and Beauregard (2018) went on to theorize understandings of the work-life interface as shaped by intersecting layers of global, national, organizational, and temporal context, noting also that there is diversity within as well as across national contexts in terms of how concepts such as 'work-life balance' are interpreted.

With regard to differences in work-life policy and practice, Ollier-Malaterre et al. (2017) considered the impact on the work-life interface not only of national culture, such as shared values, assumptions and beliefs among members of a particular nationality, but also that of a country's legal, economic and social structures, such as public policies, industrialization and gender equality. There is significant divergence between countries in terms of regulatory frameworks that support worker rights, particularly those of parents (Klarsfeld et al., 2014). Hence country context helps to determine the kind of flexible work arrangements and 'familyfriendly' policies that are available to workers (Chung, 2018). For instance, policies to support working parents are more likely to be introduced in countries higher in gender egalitarianism (Brandth and Kvande, 2015). The impact of national context on work-life supports was picked up by Beauregard et al. (2018), who theorized the influence of national context on the worklife benefits and flexible working practices that organizations provide to their employees. They posited that when a shared national culture framework influences both a) individual values and preferences for managing the work-life interface and b) the role demands of an organization set forth by its work-family culture and policies, the resulting alignment generates a coherent work-life role orientation for individuals that leads to positive outcomes in both the work and personal life domains. However, when there is misalignment, individuals experience a dissonant role orientation and the work-life interface is characterized more by conflict and compromise. 
There is also a growing amount of empirical research accounting for geographical and/or cultural context in experiences of the work-life interface. This body of work shows clearly how variation in national structures and cultural values leads to dissimilarities in how individuals' work and personal lives intersect. For example, Chatrakul Na Ayudhya et al.'s (2019) research showed how the long-lasting effects of the 2008 economic crisis and resulting austerity measures implemented by the government in Greece have both eroded managers' and professionals' sense of entitlement to a satisfactory work-life balance and weakened their capabilities for achieving such a balance. In a context of high unemployment and job insecurity, study participants spoke of working long hours and unpaid overtime and not taking up legislated entitlements such as maternity leave out of fear of losing their jobs. Pay cuts for some workers meant that they could no longer afford to travel to visit their children or their parents. The overall effect was one of reduced quality of life for these employees.

A similar lack of entitlement to work-life balance caused by different factors can be seen in Xiao and Cooke's (2012) study of workers in China, which demonstrated how economy marketization, rapid private sector growth and a national trend for work intensification results in often severe conflict between work and personal responsibilities for these individuals. Long work hours were acknowledged by employers as an issue relevant to Human Resource Management (HRM) policies, but childcare commitments were viewed as beyond the purview of organizational support. Work-life conflict thus became accepted as simply a 'fact of life' by both workers and organizational leaders. However, Zhang et al. (2014) question the extent to which Chinese workers perceive long work hours as conflicting with family responsibilities. According to Zhang and colleagues, the values of obligation and interdependence inherent to Chinese family arrangements obligate individuals to sacrifice their personal interests for the sake of the family's welfare, meaning that long work hours are experienced not as work-life conflict but as prioritization of work for family gain. Family members support those working 
long hours and the work-life interface is thus managed by the family and not by the employer or the individual.

Research in India, meanwhile, illustrates how even when employers make efforts to facilitate their workers' management of the work-life interface, cultural differences may render these ineffective. Rajan-Rankin (2016) describes how the opportunity to work from home was abandoned by male information technology workers after two weeks in which they were assumed by neighbours to be unemployed, causing shame for the workers and their household members. This study showed clearly how work-life balance initiatives offered by multinational firms headquartered in Western countries may be incompatible with local cultural values and practices.

Finally, research conducted among migrants reveals how cultural values from both the home and the host nations can intersect to influence decisions about and experiences of the work-life interface. In Khokher and Beauregard's (2014) study, expatriate Pakistani professionals in the United Kingdom made decisions about their work and personal life roles that were influenced both by their own Muslim values and by local norms for combining motherhood and paid work. Interviewees spoke of resisting pressure from extended family members to have children immediately after marriage, choosing instead to delay childbearing in favour of prioritizing work-related goals such as the completion of educational qualifications and the establishment of careers. The importance of having family members caring for young children rather than relying on childminders or nurseries was emphasized by many participants, for whom this was largely a non-negotiable condition for their envisioned return to work after maternity leave. Other research has established that individuals from cultures where intergenerational households are common, particularly in Asia, are more likely to have access to familial assistance with caregiving responsibilities (Knodel and Chayovan, 2012). For migrant working women, this assistance can be rendered by family members such as parents 
or siblings who have migrated alongside them. When migrating to a country where traditional masculine gender norms are perceived as more relaxed, male partners may also spend more time with the family and contribute to childcare and domestic work (Dyer et al., 2018).

\section{Research on the work-life interface of under-studied populations}

There is some emerging work that explores how groups of people other than the 'ideal' work-life balancer - the white, middle-class, dual-career, heterosexual, cisgender, mother of young children who performs white-collar work - experience the work-life interface. Shifting the focus from women in white-collar jobs to men in blue-collar work, Hughes and Bozionelos (2007) explored the work-life experiences of men working in a male-dominated occupation bus driving. For the study participants, a perceived imbalance between paid work and personal life was not only a source of concern but their main source of dissatisfaction. The bus drivers connected their problems with fulfilling both work and personal life commitments to work withdrawal behaviours such as using sick leave for other purposes and contemplating quitting their jobs.

Moving away from 'dual-career' to 'dual-earner' families, Warren et al. (2009) interviewed low-waged working mothers in England whose short, part-time hours of paid work were necessitated by social policies offering limited support for working parents. Social policies available to working parents elsewhere in Europe, such as universal systems of childcare and shorter working weeks, were seen by these women and their low-waged partners as enabling women's employment, improving children's quality of life, and empowering both women and men to better share childcare responsibilities and lead more balanced lives. The authors note that while the UK policy environment has moved from assumptions of a male breadwinner model to dual-earner households as a default, in reality there exist severe constraints on mothers' labour market attachment that result in women's lifetime earnings being only half that of men's. Warren builds on these findings in her 2015 paper to argue that 
while work-life balance has typically been viewed in the literature as a middle-class problem of not having enough time to fulfil both work and personal life demands, working class individuals' work-life interface is more likely to be characterized by having too few paid work hours to sustain a satisfactory personal or family life.

Social class was also pertinent to Ray and Jackson's (2013) study examining the cognitive processes of work-life decision making in terms of time pressures and perceived role demands among racially diverse Americans. The authors found that marriage and socioeconomic status provided individuals with greater social and economic capital with which to fulfil their work and family role obligations; those with more capital had more job flexibility and control over work decisions, which enabled them to better manage their family lives. Their analysis showed that married, middle-class white Americans were thus better able to manage conflicting work and family demands than either professional, Black single mothers or working class Mexican Americans. This intersectional approach to assessing work-life capabilities illustrates the combined impact of race and social class on workers' experiences of the intersection of paid work and personal life, a theme also found in Dyer et al.'s (2011) study of migrant workers in the UK healthcare and hospitality sectors. While their service sector work facilitated others' work-life balance, these workers' own management of the work-life interface was characterized by complicated strategies and negotiations necessary to meet the demands of their jobs and their caregiving responsibilities.

Another study with an intersectional lens is Kachchaf et al.'s (2015) exploration of how minority ethnic women in science, technology, engineering and mathematics academia experienced the work-life interface. The intersection of race and gender positioned these women outside the ideal worker norm, where pure dedication to scientific work left no room for personal responsibilities such as motherhood or eldercare. Career penalties arising from the tension between women's lived realities and the ideal worker norm demonstrated very clearly 
that these women's work-life experiences were noticeably different from those of colleagues who more closely embodied the norm. Similarly, Hamidullah and Riccucci's (2017) study of workers' satisfaction with employer work-life balance policies found that race, educational attainment, and age all played a role in determining women's perceptions of fairness with regard to the initiatives on offer. The researchers noted that because over half of African American children live in single-parent households headed by women who often rely on family and friends to assist with childcare, organizational policies designed to help workers manage family responsibilities are particularly attractive to female African American employees.

\section{Research on diverse working arrangements impacting the work-life interface}

'Work-life balance' or 'family-friendly' policies addressing the work-life interface have become increasingly mainstreamed among employers. Even in the Western context where these policies originated, however, not all categories of worker in all organizational types benefit equitably from policies and neither are all organizations equally enlightened in offering work-life initiatives. There are significant differences in policy availability based on unionization, size of organization, degree of formality of HRM and labour market substitutability of workers - and therefore the relative importance of retention as an incentive for employers to offer support for the work-life interface (Van Wanrooy et al., 2013). The availability of, for example, telework arrangements could be assumed to be higher for a professional on an open-ended, permanent contract of employment working in a large organization with a formalized HRM function and union recognition agreement, than for a seasonal worker on a fixed-term, freelance arrangement working in a small workplace in the hospitality sector. Recent scholarship on non-standard working arrangements tackles familiar initiatives such as telework and flexible hours but also looks at flexible working practices less frequently studied in the context of the work-life interface, such as shift work and compressed work weeks. There is also emerging research examining work-life experiences within newer 
working models, such as portfolio careers and gig work generated by the digital platform economy, and in nonstandard workplaces, such as oil rigs and brothels.

With the coronavirus pandemic ushering in heretofore unseen levels of working from home in 2020, research on this particular practice is likely only to increase. Encouragingly, Richardson and McKenna's (2014) study of Canadian high-tech employees who engaged in frequent telework demonstrated how instead of their homes being 'invaded' by work, individuals actively redefined and reorganized both their work and home spaces to meet their changing needs as their work patterns evolved. The function and purpose of these spaces were often reconstructed, with work being conducted at home and socializing becoming a key rationale for visiting the office. For organizations where telework is deeply embedded, unexpected challenges may arise. Full-time teleworkers in Beauregard et al.'s (2019) study reported high levels of organizational commitment, with most intending to serve out their working lives with their current employer, but the flip side of this loyalty was a deep-seated reluctance to progress their careers if that might require working more often from the office instead of at home. Even for workers with high levels of career ambition, weighing the lifestyle implications of frequent commuting against the incentives of higher pay and more challenging work offered by a promotion did not produce an acceptable cost-benefit ratio. Managers and colleagues of full-time teleworkers noted that while beneficial for individual workers, widespread take-up of this practice had negative implications for the organization in terms of succession planning.

For those who are self-employed rather than employees, working from home does not always have a positive impact on lifestyle and time with family members. Kapasi and Galloway's (2015) study of individuals operating home-based businesses shows that while an improved work-life balance was the predominant motivating factor for most of the participants to start their own businesses, and most were of the view that their work-life interface was easier 
to manage as an entrepreneur than in their former lives as employees, many struggled on an ongoing basis with fulfilling competing work and personal life demands. The flexibility offered by combining work and home space and time, and the autonomy afforded by self-employment, were helpful resources in efforts to meet multiple role demands but required considerable planning and self-discipline alongside. The researchers concluded that home-based business ownership was not in itself a solution to work-life conflict. Rather, it can more realistically be viewed as an alternative form of employment within which to develop strategies to manage the work-life interface.

Other non-standard working time arrangements have also been investigated in relation to their impact on the work-life interface. For instance, Bambra et al.'s (2008) review of compressed work weeks concluded that its usage could be beneficial to shift workers' worklife balance with a low risk of adverse effects to individuals' health or to organizational effectiveness. Shift work in general, however, has been found to exert a negative effect on work-life balance, with evening work and Saturday work posing substantial constraints on social and family participation, and evening work also leading to higher levels of work-related health complaints (Greubel et al., 2016). Unpaid overtime can have similar effects; Virick et al.'s (2007) research found that survivors of layoffs in a high-tech firm were subject to increased workloads that were experienced as role overload. The negative impacts on worklife balance reduced workers' job and life satisfaction in turn, diminishing overall quality of life for these individuals.

Emerging research on non-standard work models paints a picture of wide variation in experiences of the work-life interface, with worker agency over these experiences similarly variable. In Teague et al.'s (2015) study of musicians who had developed portfolio careers, made up of many different jobs, participants described how beneficial they found flexible, entrepreneurial working to be for their work-life balance. Teaching, fixed-location musical 
theatre work and operating one's own company were seen as highly compatible with family life and ability to meet demands from the domestic sphere. However, the most lucrative source of revenue for most musicians was touring, which was also perceived as least suitable for maintaining relationships and fulfilling caregiving responsibilities. Satisfactory management of the work-life interface therefore necessitated financial trade-offs. Lehdonvirta's (2018) research of gig platform workers also found evidence of trade-offs between work-life balance and income. Autonomy over work scheduling was seen as a key benefit of gig work and conducive to accommodating personal life commitments alongside work tasks. However, control over scheduling was only possible when sufficient work tasks were available and workers were not entirely dependent on these for their living. When the availability of piecework tasks was limited, workers without access to complementary sources of income found themselves constantly on call, in some cases sleeping only in short bursts in front of their computers so as not to miss out on suitable work opportunities. In these cases, autonomy disappeared and workers were forced into a binary choice between earning a living and having time to spend in non-work pursuits.

Finally, another focus of recent research has been on how individuals in non-standard workplaces, where workers live on-site, experience work and personal life roles as segmented (separate) versus integrated (combined). Blithe and Wolfe's (2016) study of Nevada's legal brothel industry found that due to local regulations and discrimination from community service providers, sex workers engaged in nearly complete segmentation of work and personal life roles. Although sex workers are considered independent contractors and determine the length of their own contracts, most brothels enforced policies that require workers to stay on-site during their contract period, complemented by county regulations that often specified when or if sex workers are allowed to be in town or have family members residing there. As failure to observe these regulations could result in termination of working privileges, sex workers 
reported widespread compliance. On-site provision of healthcare, financial, and shopping services often denied to them in the community helped workers cope with occupational stigma and simultaneously strengthened boundaries between the domains of paid work and personal life, with children and other family members living in other towns and frequently not seen for weeks or months at a time.

This extreme version of work-life segmentation is echoed in the offshore workers from Basile and Beauregard's (2018) study of fit and misfit between worker preferences for segmentation and organizational supply. Workers were subject to lengthy rotations away from home followed by long periods away from work and had limited access to reliable telecommunications between domains. For workers whose preferences were for greater integration of work and personal life roles, this highly segmented work-life interface generated conflict between the behaviours used in work and personal life roles and reduced the extent to which work and personal life roles were perceived as enriching one another. Misfit also resulted in lower levels of commitment to the organization, raising for employers the spectre of withdrawal or turnover.

\section{Articles in this Special Issue}

The six articles presented in this special issue span the themes identified above. They present, in themselves, a diversity of approaches to studying the work-life interface. With regard to research on the work-life interface in diverse geographical and cultural contexts, Comparing the situation- and person-based predictors of work-family conflict among married working professionals in India by Rupashree Baral helps to address the issue that despite India being the world's second most populous nation and its economy fast-developing, its citizens remain under-represented in work-life research. Baral tests the ability of core self-evaluations (self-esteem, self-efficacy, emotional stability and locus of control) to predict conflict between work and family roles among professionals in India's manufacturing and services sector, and 
compares their impact to that of situational factors such as working hours, caregiving responsibilities for young children, and social and organizational supports. Dispositional factors accounted for greater variance in the study participants' family-to-work conflict, whereas situational factors were stronger predictors of work-to-family conflict. These findings reinforce the importance of employer efforts to assist workers' efforts to manage the work-life interface, as the extent to which work responsibilities interfere with personal commitments depends in larger part upon situational characteristics that in many cases will be responsive to organizational interventions.

Also accounting for geocultural diversity in the work-life interface is Irina Gewinner's Work-life balance for native and migrant scholars in German academia: Meanings and practices. Here, perceptions of the work-life interface for highly skilled migrant scholars from the former Soviet Union are differentiated from those of native German academics by migrants' cultural capital and the migration experience itself. Particularly distinctive were the culturallyrooted differences between migrant and native academics in terms of attitudes toward family formation as either a parallel or sequential priority in relation to career planning. While the native German participants connected maturity with a permanent employment contract and a solid financial underpinning from which to build a family, their Russian-speaking counterparts associated adulthood with having children rather than with achieving financial stability and were thus more likely to be younger parents. However, many of the migrant academics found themselves reprioritizing work-life decisions once faced with competing cultural norms and associated constraints in the German context, illustrating the significance of contextual factors on the work-life interface.

Addressing the work-life interface of under-studied populations, Work-to-family and family-to-work conflicts among employed single parents in Germany by Mareike Reimann, Charlotte Marx and Martin Diewald analyses the impact of job and family demands and 
resources on work-family conflict among single parents compared to parents in couple families. Contrary to expectations, single parents did not report more work-to-family conflict than parents in couple families, but they did report significantly more family-to-work conflict, particularly when they relied on formal childcare arrangements. This illustrates the inadequacy of public childcare provision in some regions in Germany, which can be difficult to access close to home or work and whose opening hours are often not as long as a standard working day. Notably, working from home increased work-to-family conflict for all parents in the study, regardless of household composition.

Picking up on the topic of working practices that can facilitate or hinder efforts to manage the work-life interface, Improving work-life policy and practice with an intersectionality lens by Ann Marie Ryan and Caitlin Briggs examines the assumptions that lie behind mainstream work-life balance policies in organizations and suggests ways to formulate genuinely inclusive work-life practices. For example, they recommend organizational leaders adopting a stance of 'tempered visibility' in identifying the work-life needs of workers from diverse backgrounds; this recognizes that either rendering intersectional aspects of identity invisible or stigmatizing individuals through hypervisibility both lead to a failure in recognizing the work-life needs that workers' specific circumstances necessitate. Ryan and Briggs also highlight the importance of recognizing that issues of 'authenticity' in a context of 'impression management' can be exercised in a way to allow each individual to be safe in the workplace and be able to contribute without needing to demonstrate some form of cultural conformance. They acknowledge the tensions inherent in many of these areas, however, such as ensuring that the use of inclusive language to promote work-life policies not replicate previous 'colour-blind' efforts that deny systemic inequalities between groups of workers.

With regard to diverse working arrangements that impact the work-life interface, Supporting work-life balance with the use of coworking spaces by Marko Orel presents a four- 
country study of the niche work environment of parent entrepreneurs' coworking spaces. Sharing work space with proximity to childcare facilities is perceived by study participants to provide a far more optimal work-life balance than more conventional working arrangements, including working from home - which we have seen from research reviewed earlier in this article to present its own challenges as well as benefits. A more extreme working arrangement is explored in The work-life experiences of an invisible workforce: The case of live-in women migrant domestic workers in Malaysia by Wee Chan $\mathrm{Au}$, Uracha Chatrakul $\mathrm{Na}$ Ayudhya and Pervaiz Ahmed. This study of migrant domestic workers in Malaysia explores the impact on women's work-life interface of leaving their own family in the home country to care for their employer's children - and live in their employer's home - in the host country. The facilitation of professional Malaysians' pursuit of career and parenthood relies on imported labour from lower-income neighbouring countries, and the ability of migrant domestic workers to financially support their families comes at the expense of their ability to live with them. The work-life interface for these workers is thus heavily weighted toward work, with very little time or space available for personal commitment.

\section{The importance of intersectionality in future work-life interface research}

The divergence in experiences of the work-life interface based on national and organisational context is compounded by individual characteristics of workers along the equality and diversity attributes familiar to readers of this journal. This combines to mean that the experience of WLB needs to be understood in the context of intersectionality, the starting premise of which is that people have multiple identities based on demographic characteristics such as gender, race, social class, religion, and sexual orientation (Crenshaw, 1991). These identities are determined by history, geographical location, culture and social relations and combine to produce substantively distinct experiences for individuals (McCall, 2005). As can be seen by the literature reviewed earlier in this article and the new research featured in this 
Special Issue, an intersectional approach is instrumental in helping us capture the diversity of workers' situations and how they negotiate the intersection between work and personal life roles within the context of organizational and societal practices.

An increasing amount of scholarship is tackling the gaps and blind spots in the worklife literature by examining the experiences of under-studied groups of workers or by situating its investigations in under-studied locations. An explicit intersectional lens has recently been used to frame discussion on topics such as the work-life balance experiences of Muslim migrant women and of Asian foreign-born female scholars in western contexts (Ali et al., 2017; Lee and Lenoir, 2016), the financial and cultural challenges faced by migrants who have caregiving responsibilities in their countries of origin (Dyer et al., 2018), and the impact of family support on Moroccan women's entrepreneurship (Constantinidis et al., 2018). For this necessary trend to continue, scholars must build intersectionality into their research designs. Ignoring intersectionality risks excluding employee groups, such as immigrant workers, those from ethnic and religious minorities, workers with disabilities, and those with non-traditional family structures, from investigation. Conversely, understanding their work-life experiences - how minority workers manage work and personal life roles, the opportunities and obstacles they face, what arrangements are required to meet their needs can guide organizations in developing inclusive and equitable policies and improving retention. For researchers, this means a valuable opportunity to "imagine other places to which the theory might be taken" (Carbado et al., 2013, p. 303), extending the boundaries of current work-life interface research.

\section{References}

Abraham, K. G., Haltiwanger, J. C., Sandusky, K., \& Spletzer, J. R. (2018). Measuring the gig economy: Current knowledge and open issues (No. w24950). National Bureau of Economic Research. 
Ali, F., Malik, A., Pereira, V., \& Al Ariss, A. (2017). A relational understanding of work-life balance of Muslim migrant women in the west: future research agenda. The International Journal of Human Resource Management, 28(8), 1163-1181.

Bambra, C., Whitehead, M., Sowden, A., Akers, J., \& Petticrew, M. (2008). “A hard day’s night?" The effects of Compressed Working Week interventions on the health and worklife balance of shift workers: A systematic review. Journal of Epidemiology \& Community Health, 62(9), 764-777.

Basile, K. A., \& Beauregard, T. A. (2018). Oceans apart: Work-life boundaries and the effects of an oversupply of segmentation. Forthcoming in International Journal of Human Resource Management. doi: 10.1080/09585192.2018.1512513

Beauregard, T. A., Basile, K. A., \& Thompson, C. A. (2018). Organizational culture in the context of national culture. In R. Johnson, W. Shen, \& K. M. Shockley (Eds.), The Cambridge handbook of the global work-family interface (pp. 555-569). Cambridge: Cambridge University Press.

Beauregard, T. A., Canónico, E., \& Basile, K. A. (2019). “The fur-lined rut”: Telework and career ambition. In C. Kelliher \& J. Richardson (Eds.), Work, working and work relationships in a changing world (pp. 17-36). Abingdon, Oxfordshire: Routledge.

Beigi, M., Wang, J., \& Arthur, M. B. (2017). Work-family interface in the context of career success: A qualitative inquiry. Human Relations, 70(9), 1091-1114.

Blithe, S. J., \& Wolfe, A. W. (2016). Work-life management in legal prostitution: Stigma and lockdown in Nevada's brothels. Human Relations, 70(6), 725-750.

Brandth, B., \& Kvande, E. (2015). Parental leave and classed fathering practices in Norway. In Eydal, G. B., \& Rostgaard, T. (Eds.), Fatherhood in the Nordic welfare states: Comparing care policies and practices (pp. 121-140). Bristol, UK: Policy Press. 
Cannizzo, F., Mauri, C., \& Osbaldiston, N. (2019). Moral barriers between work/life balance policy and practice in academia. Journal of Cultural Economy, 12(4), 251-264.

Carbado, D. W., Crenshaw, K. W., Mays, V. M., \& Tomlinson, B. (2013). Intersectionality: Mapping the movements of a theory. Du Bois Review: Social Science Research on Race, 10(2), 303-312.

Carlson, D. S., Grzywacz, J. G., \& Zivnuska, S. (2009). Is work-family balance more than conflict and enrichment? Human Relations, 62(10), 1459-1486.

Chandra, V. (2012). Work-life balance: Eastern and western perspectives. The International Journal of Human Resource Management, 23(5), 1040-1056.

Chatrakul Na Ayudhya, U., Prouska, R., \& Beauregard, T. A. (2019). The impact of global economic crisis and austerity on quality of working life and work-life balance: A capabilities perspective. European Management Review, 16(4), 847-862.

Chung, H. (2018). Dualization and the access to occupational family-friendly working-time arrangements across Europe. Social Policy and Administration, 52(2), 491-507.

Constantinidis, C., Lebègue, T., El Abboubi, M., \& Salman, N. (2019). How families shape women's entrepreneurial success in Morocco: An intersectional study. International Journal of Entrepreneurial Behavior \& Research, 25(8), 1786-1808.

Crenshaw, K. (1991). Mapping the margins: Intersectionality, identity, and violence against women of color. Stanford Law Review, 43(6), 1241-1300.

Cruz, D., \& Meisenbach, R. (2018). Expanding role boundary management theory: How volunteering highlights contextually shifting strategies and collapsing work-life role boundaries. Human Relations, 71(2), 182-205.

Derks, D., Bakker, A. B., Peters, P., \& van Wingerden, P. (2016). Work-related smartphone use, work-family conflict and family role performance: The role of segmentation preference. Human Relations, 69(5), 1045-1068. 
Drummond, S., O’Driscoll, M. P., Brough, P., Kalliath, T., Siu, O. L., Timms, C., ... \& Lo, D. (2017). The relationship of social support with well-being outcomes via work-family conflict: Moderating effects of gender, dependants and nationality. Human Relations, $70(5), 544-565$.

Dyer, S., McDowell, L., \& Batnitzky, A. (2011). Migrant work, precarious work-life balance: What the experiences of migrant workers in the service sector in Greater London tell us about the adult worker model. Gender, Place \& Culture, 18(5), 685-700.

Dyer, S., Xu, Y. and Sinha, P. (2018), Migration: A means to create work-life balance? Journal of Management and Organization, Vol. 24 No. 2, pp. 279-294

Ford, J., \& Collinson, D. (2011). In search of the perfect manager? Work-life balance and managerial work. Work, Employment and Society, 25(2), 257-273.

French, K. A., Dumani, S., Allen, T. D., \& Shockley, K. M. (2018). A meta-analysis of work-family conflict and social support. Psychological Bulletin, 144(3), 284-314.

Gatrell, C. J., Burnett, S. B., Cooper, C. L., \& Sparrow, P. (2013). Work-life balance and parenthood: A comparative review of definitions, equity and enrichment. International Journal of Management Reviews, 15(3), 300-316.

Greenhaus, J. H., \& Allen, T. D. (2011). Work-family balance: A review and extension of the literature. In J. C. Quick and L. E. Tetrick (Eds.), Handbook of occupational health psychology, $2^{\text {nd }}$ ed. (pp.165-183). Washington, DC: American Psychological Association

Greubel, J., Arlinghaus, A., Nachreiner, F., \& Lombardi, D. A. (2016). Higher risks when working unusual times? A cross-validation of the effects on safety, health, and work-life balance. International Archives of Occupational and Environmental Health, 89(8), 1205 1214.

Guillaume, C., \& Pochic, S. (2009). What would you sacrifice? Access to top management and the work-life balance. Gender, Work \& Organization, 16(1), 14-36. 
Hamidullah, M.F., \& Riccucci, N.M. (2017). Intersectionality and family-friendly policies in the federal government: Perceptions of women of color. Administration \& Society, 49, 105- 120.

Hampden-Turner, C. M., \& Trompenaars, F. (2008). Building cross-cultural competence: How to create wealth from conflicting values. New Haven, CT: Yale University Press.

Healy, J., Nicholson, D., \& Pekarek, A. (2017). Should we take the gig economy seriously? Labour \& Industry: A journal of the social and economic relations of work, 27(3), 232-248.

House, R. J., Hanges, P. J., Javidan, M., Dorfman, P. W., \& Gupta, V. (Eds.). (2004). Culture, leadership, and organizations: The GLOBE study of 62 societies. London: SAGE.

Hughes, J., \& Bozionelos, N. (2007). Work-life balance as source of job dissatisfaction and withdrawal attitudes: An exploratory study on the views of male workers. Personnel Review, 36(1), 145-154.

Kachchaf, R., Ko, L., Hodari, A., \& Ong, M. (2015). Career-life balance for women of color: Experiences in science and engineering academia. Journal of Diversity in Higher Education, 8(3), 175-191.

Kapasi, I., \& Galloway, L. (2015). Work-life balance in home-based businesses: A UK Study. The International Journal of Entrepreneurship and Innovation, 16(1), 33-42.

Kelliher, C., Richardson, J., \& Boiarintseva, G. (2019). All of work? All of life? Reconceptualising work-life balance for the 21 st century. Human Resource Management Journal, 29(2), 97-112.

Khokher, S. Y., \& Beauregard, T. A. (2014). Work-family attitudes and behaviours among newly immigrant Pakistani expatriates: The role of organizational family-friendly policies. Community, Work \& Family, 17(2), 142-162. 
Klarsfeld, A., Booysen, L. A., Ng, E., Roper, I., \& Tatli, A. (Eds.). (2014). 9.78 E+ 12: Country Perspectives on Diversity and Equal Treatment. Edward Elgar Publishing.

Knodel, J., \& Chayovan, N. (2012). Inter-generational family care for and by older people in Thailand. International Journal of Sociology and Social Policy, 32(11/12), 682-694.

Kossek, E. E., Lewis, S., \& Hammer, L. B. (2010). Work-life initiatives and organizational change: Overcoming mixed messages to move from the margin to the mainstream. Human Relations, 63(1), 3-19.

Kurowska, A. (2018). Gendered effects of home-based work on parents' capability to balance work with nonwork. Two countries with different models of division of labour compared. Social Indicators Research. https://doi.org/10.1007/s11205-018-2034-9

Lee, P. L., \& Lenoir, G. C. (2016). Asian foreign-born women scholars experience a triple threat to work-life balance. In K. C. Mansfield, A. D. Welton \& P.-L. Lee (Eds.), Identity Intersectionalities, Mentoring, and Work-Life (Im) Balance: Educators (Re) Negotiate the Personal, Professional, and Political (pp. 191-204). Charlotte, NC: Information Age Publishing.

Lehdonvirta, V. (2018). Flexibility in the gig economy: managing time on three online piecework platforms. New Technology, Work and Employment, 33(1), 13-29.

Lewis, S., \& Beauregard, T. A. (2018). The meanings of work-life balance: A cultural perspective. In R. Johnson, W. Shen, \& K. M. Shockley (Eds.), The Cambridge handbook of the global work-family interface (pp. 720-732). Cambridge: Cambridge University Press.

Lupu, I., Spence, C., \& Empson, L. (2018). When the past comes back to haunt you: The enduring influence of upbringing on the work-family decisions of professional parents. Human Relations, 71(2), 155-181. 
Masuda, A. D., Sortheix, F. M., Beham, B., \& Naidoo, L. J. (2019). Cultural value orientations and work-family conflict: The mediating role of work and family demands. Journal of Vocational Behavior, 112, 294-310.

McCall L (2005) The complexity of intersectionality. Signs: Journal of Women in Culture and Society 30(3): 1771-1800

Mortazavi, S., Pedhiwala, N., Shafiro, M., \& Hammer, L. (2009). Work-family conflict related to culture and gender. Community, Work \& Family, 12(2), 251-273.

Ollier-Malaterre, A., \& Foucreault, A. (2017). Cross-national work-life research: Cultural and structural impacts for individuals and organizations. Journal of Management, 43(1), 111136.

Özbilgin, M. F., Beauregard, T. A., Bell, M. P., \& Tatli, A. (2011). Work-life, diversity and intersectionality: A critical review and research agenda. International Journal of Management Reviews, 13(2), 177-198.

Powell, G. N., Francesco, A. M., \& Ling, Y. (2009). Toward culture-sensitive theories of the work-family interface. Journal of Organizational Behavior, 30(5), 597-616.

Rajan-Rankin, S. (2016). Paternalism and the paradox of work-life balance: Discourse and practice. Community, Work \& Family, 19(2), 227-241.

Ray, R. \& Jackson, P.B. (2013). Intersectionality and work-family balance: A study of Black, White, and Mexican-American adults. Advances in Gender Research, 17, 241-262.

Richardson, J., \& McKenna, S. (2014). Reordering spatial and social relations: A case study of professional and managerial flexworkers. British Journal of Management, 25(4), 724736.

Teague, A., \& Smith, G. D. (2015). Portfolio careers and work-life balance among musicians: An initial study into implications for higher music education. British Journal of Music Education, 32(2), 177-193. 
Van Wanrooy, B., Bewley, H., Bryson, A., Forth, J., Freeth, S., Stokes, L., \& Wood, S. (2013). The 2011 workplace employment relations study: First findings. London: Department for Business, Innovation \& Skills.

Virick, M., Lilly, J. D., \& Casper, W. J. (2007). Doing more with less: An analysis of worklife balance among layoff survivors. Career Development International, 12(5), 463-480.

Voydanoff, P. (2002). Linkages between the work-family interface and work, family, and individual outcomes: An integrative model. Journal of Family Issues, 23, 138-164.

Warren, T. (2015). Work-life balance/imbalance: the dominance of the middle class and the neglect of the working class. The British Journal of Sociology, 66(4), 691-717.

Warren, T., Fox, E., \& Pascall, G. (2009). Innovative social policies: Implications for worklife balance among Low-waged women in England. Gender, Work \& Organization, 16(1), 126-150.

Xiao, Y., \& Cooke, F. L. (2012). Work-life balance in China? Social policy, employer strategy and individual coping mechanisms. Asia Pacific Journal of Human Resources, 50(1), 6-22.

Zhang, M., Li, H., \& Foley, S. (2014). Prioritizing work for family: A Chinese indigenous perspective. Journal of Chinese Human Resource Management, 5(1), 14-31. 